\title{
Capturing architects' designerly ways of knowing about users: Exploring an ethnographic research approach
}

\author{
Valerie Van der Linden ${ }^{\mathrm{a}^{*}}$, Hua Dong ${ }^{\mathrm{b}}$, Ann Heylighen ${ }^{\mathrm{a}}$ \\ ${ }^{\mathrm{a}} \mathrm{KU}$ Leuven, Belgium \\ ${ }^{\text {b} T o n g j i ~ U n i v e r s i t y, ~ C h i n a ~}$ \\ *Corresponding author e-mail: valerie.vanderlinden@kuleuven.be
}

\begin{abstract}
Transferring knowledge about diverse users' experiences from research into architectural design practice is not straightforward. Effective knowledge transfer requires taking into account architects' design practice. This paper explores a research approach to gain insight into architects' designerly ways of knowing about users. It discusses why an ethnographic research approach offers a means to study a culture of practice such as architectural design practice. A fieldwork account from a pilot study in an architecture firm provides insight into the experiential issues architects deal with. It illustrates how fieldwork techniques can be applied to map the socio-material aspects (e.g., different stakeholders and design materials) that mediate knowledge about users. Exploiting these aspects of architectural design practice is expected to open new ways of thinking about informing architects about users' experiences. For instance, there lies an opportunity in engaging architects' creative representational skills, which challenges architects' and researchers' roles in knowledge transfer.
\end{abstract}

Keywords: architectural design; ethnography; knowledge; research methodology

\section{Introduction}

Architectural design processes are becoming increasingly complex due to the various requirements (e.g., sustainability, accessibility, heritage value) and the constellation of stakeholders involved (e.g., client bodies, consultants, contractors). Especially in large-scale projects, client and end-users typically do not coincide. ${ }^{1}$ Since the industrial revolution introduced a dichotomy between design processes and use practices (Redström 2012), the

\footnotetext{
${ }^{1}$ We are aware of the critique on the notion of "users". Yet, for lack of a more appropriate term, we will use this as shorthand for "people who use the building or space whom architects design for".
} 
gap between designers' intent and users' actual experience has grown (Crilly, Maier and Clarkson 2008).

Architects are expected to conceive buildings and spaces with an eye to offering people a future experience, often without having access to their motivations, values and experiences. Yet how can an architect grasp what "home" means to people with dementia, or "healing environment" to people affected by cancer? Designing for "the other" is challenging, because others' spatial experience can considerably differ from architects' due to differences in age, gender, ability, ethnicity, profession, situation, etc. (Imrie 2003). A crucial competence for designers is thus being able to empathize with future users (Dorst 2006; Formosa 2009). To this end, architects need sources that inform them about diverse users' spatial experience and needs (Annemans, et al 2014).

Our research aims to address the challenge of transferring knowledge about users' experiences into architectural design practice. As identified by various authors, the knowledge generated by traditional research mismatches the knowledge required in architectural design practice (Diaz Moore and Geboy 2010; Kirkeby 2009; Rashid 2013). We argue that the lack of effective ways to communicate users' spatial experience and needs to architects relates to a lack of attention to architects' "designerly ways of knowing" (Cross 2006) in research methodology. Our overall goal is to develop more effective information formats by tying in with architects' design practice.

Currently, little is known about architects' particular ways of knowing about users. The most obvious methods to study architects' information handling are questionnaires and interviews (e.g., Bogers, van Meel and van der Voordt 2008; Kirkeby 2015; Tétreault and Passini 2003; Weytjens, Verdonck and Verbeeck 2009). As these rely on self-reporting, they risk a diverted presentation of the design process (Lawson 1994, p.2), and provide little insight into how knowledge about users is embedded in architects' design practice. This paper starts from an understanding of design as a process situated in and distributed across a socio-material environment (Heylighen and Nijs 2014). Acknowledging the mediating role of different stakeholders and design materials implies that they should be taken into account when studying architects' designerly ways of knowing about users.

An ethnographic research approach has proven valuable to gain insight into architects' practice (predominantly in social studies of science and organisation studies) (cf. Christensen 2013; Cuff 1992; Ewenstein and Whyte 2009; Kasalı and Nersessian 2015; Kornberger, Kreiner and Clegg 2011; Luck 2007; Yaneva 2009). We argue that such an approach has the potential to provide the kind of results required for our more applied study, which aims at developing design-oriented information formats.

The aim of this paper is to explore a research approach that allows gaining insight into architects' designerly ways of knowing about users. Based on an understanding of design as a socio-material process (section 2), we argue for an ethnographic research approach to study a "culture of practice" such as architectural design practice (section 3). Next, an 
account from a pilot study in an architecture firm illustrates the application of fieldwork techniques such as participant observation, interviews and analysis of design materials to capture architects' designerly ways of knowing about users (section 4). We discuss how the kind of results generated through these ethnographic techniques allows for an in-depth understanding of the social and material aspects of architectural design practice (section 5). Subsequently, the practical possibilities and limitations of the ethnographic research approach are discussed (section 6). Insights from our study are expected to inform the development of design-oriented information formats to effectively transfer knowledge about users' experiences into design practice.

\section{Design as a socio-material process}

If our ultimate aim is to inform architects' design process about users' experiences, it is important to acknowledge that "design has its own distinct 'things to know, ways of knowing them, and ways of finding out about them"' (Cross 2006, p.17). An important characteristic is that designers do not conduct extensive research, but address design problem and solution simultaneously (Cross 2006; Lawson 1994; Rittel and Webber 1973; Schön 1983). The particular nature of design in general affects designers' ways of handling information and their preferences concerning its content and type. For instance, designers prefer information that is descriptive and design-relevant, whereas they dislike prescriptive rules or extensive reports (Annemans, et al 2014; Dong, et al 2015; Goodman, Langdon and Clarkson 2006; Nickpour and Dong 2011). The omnipresent standards and regulations are criticised by architects for offering little insight, restricting their creativity and taking away their challenge to come up with intelligent solutions (Gray, Gould and Bickenbach 2003).

Given architects' selective information uptake (Newland, Powell and Creed 1987) attention should be paid to the information format. It is important to understand "information format" in a broader sense than a type of document. Focussing on the characteristics of information only would isolate information from the practice in which it is used. In reality the interrelation between designers and information is more complex. For example, designers can hold certain predispositions regarding information that are not related to the characteristics of the information itself, but rather derive from their status, background or habits (Lera, Cooper and Powell 1984).

Nowadays, designing is increasingly understood as situated in and distributed across a sociomaterial environment (Heylighen and Nijs 2014). Design is rather a team than an individual activity (Valkenburg and Dorst 1998). Moreover, as mentioned, designers increasingly collaborate with other stakeholders. The way the client translates user needs, e.g., can impact on architects' design process (Van der Linden, Annemans and Heylighen 2016). Attention to users' spatial experience can be facilitated or hampered also by the material context. This includes the design materials used in this collaboration, such as photographs, sketches, physical and CAD-models. Designers reflect-in-action on potential solutions by manipulating design materials and incorporating their "back-talk" (Schön 1983). 
Our research sets out to study in depth how architectural design practice attends to people's spatial experience. Contemporary understandings of design direct our research focus to examining how architects' socio-material environment mediates their attention for users. This broadens our perspective from information characteristics to how knowledge about people's spatial experience and needs is generated, shared, transformed and represented. If ultimately we want to develop information formats that tie in with architects' designerly ways of knowing, our research methods should allow taking into account the preconditions set by the socio-material environment in which architects work.

\section{An ethnographic research approach}

Ethnography is the systematic study of a culture of people, traditionally applied by anthropologists (Boas 1920). The culture we want to study here is not one that originates from a shared ethnological background, rather it is a "culture of practice", originating form a shared professional situation. Architectural researcher Dana Cuff (1992) argues that considering architectural design practice as a culture creates the perfect opportunity for an in-depth examination:

\footnotetext{
"Use of the concept of culture fosters a certain kind of analysis, one that looks closely at people's everyday lives, their situated actions, as well as what they say and the meaning they construct. ... an ethnography ties ideas about the group's knowledge, its beliefs, its social organization, how it reproduces itself, and the material world in which it exists. These guidelines for studying "unfamiliar" cultures apply equally well to those communities that we encounter every day." (Cuff 1992, p.5)
}

An ethnographic research approach has been frequently adopted in social studies of science, to study the cultures of practice of, e.g., laboratory workers (Latour and Woolgar 1986). Researchers with backgrounds in social sciences and/or design have conducted studies about engineering designers (Bucciarelli 1988; Lloyd 2000; Vinck 2009) and even architects (Cuff 1992; Yaneva 2009). Also organisation and management studies have borrowed from ethnography to study architecture firms (Ewenstein and Whyte 2009; Kornberger, et al 2011). All these studies have adopted the basics of ethnography to capture an insider's view on a particular culture of practice.

Pioneer-anthropologist Bronisław Malinowski (1922/1984) is known as the first to elaborate on ethnographic research methods that allow grasping the participants' point of view. He suggests initially focusing attention on tools, skills and material cultures through careful observation. This may reveal cultural habits and the so-called "imponderabilia" or characteristic details of daily life. In the second instance, he suggests, the meaning of these observed aspects be understood through statements and narratives of participants.

Indeed, as a culture is embodied in "mundane" body techniques, people may find it difficult to explain their commonplace or routine activities. As these activities appear obvious to themselves, or are even taken for granted, they are hard to be aware of. Relying solely on interviews would allow shedding a light on the shared vocabulary, attitudes and values of 
the culture, but it would render many meaningful aspects invisible. Or as Tony Watson (2011) states in his plea to apply ethnography in organisation and management studies:

"we cannot really learn a lot about what 'actually happens' or about 'how things work' in organizations without doing the intensive type of close-observational or participative research that is central to ethnographic endeavour" (p.204)

Linden Ball and Thomas Ormerod (2000) point out three reasons to apply ethnographic fieldwork techniques in studying design practice. First, an ethnographic approach takes into account the complex nature of real-world design, which renders experimental research methods inappropriate. Second, it takes into account the social context instead of just focussing on individual behaviour. And finally, it has the capacity to track ad hoc decision making and interactions outside the official realm, e.g., during coffee breaks.

A study of everyday practices as they take place in their own socio-material environment allows paying attention to skills, tools, narratives and commonplace activities. The most important data collection techniques in ethnographic fieldwork are participant observation, in-depth interviews and document analysis. They allow collecting contextualised, detailed, experience-rich data. Assembling observations of architects' everyday ways of working and skills with narratives from in-depth interviews and an analysis of design materials, is expected to produce insights into their designerly ways of knowing. As such we aim to understand how knowledge about people's spatial experience is generated, shared, transformed and represented within architectural design practice.

\section{Fieldwork account}

This paper reports on a pilot study in a Brussels-based architecture firm, set up to explore the possibilities and limitations of the research approach and produce preliminary results (which will be further investigated in studies of different architecture firms). At the time of the study, the firm consisted of nine architects, including two partners and two interns. The firm's portfolio mainly consists of public buildings and collective housing projects. Many projects are granted through competitions. The first author conducted fieldwork during a six-week research stay in fall/winter 2014, when she was present in the firm on a part-time basis. Her presence was negotiated with the two partners, who stated that "it's nice that someone comes and looks how [architects] work, [in order to] really understand". The researcher's identity was not covered. She briefly presented herself and her aim (to study knowledge in architectural design practice) on the first day.

The researcher was offered a desk in the workplace that was shared by all architects except for the partners. She was granted access to internal and external design meetings and to all design documentation in the firm. She also conducted in-depth interviews with five architects on (knowledge in) the projects they were currently working on. As such, the researcher could observe architects' everyday ways of working (documented in field notes) and complement these with interviews (audio recorded and transcribed) and design materials. Insights were constructed through thematic analysis of the different data. 
In this section, four episodes from the fieldwork account illustrate how this research approach allowed investigating architects' ways of knowing about users, with specific attention to architects' socio-material environment. The account focuses on one architect and the main project he was working on. As the design process was ongoing, it has been partly reconstructed through interviews and an analysis of design materials. Interview quotes were translated by the authors.

\subsection{Grasping the project aim}

Nick (pseudonym) is an architect with ten years of experience. He started working in the firm a few months before the study. He was responsible for the design of a town hall (transformation and extension) for a small, rural municipality in Belgium, which had been granted through a competition before he joined the firm. Nick recalled that he was briefed on the project's concept orally by the firm's partner and further browsed the existing documents like the competition entry on his own.

Due to the lack of a clear design brief, Nick found it hard to grasp the project's requirements. The project documentation included a 40-page concept note, drawn up by the client, stating the project's aim and reporting on internal and external surveys and group discussions concerning the services of the new town hall. The researcher noticed that the most specific aspects, relating to measures, atmospheres and particular use scenarios, had been marked by the architect who worked on the project during the competition stage. However, the information was not complete. The concept note proved of little use to Nick. It did not give him any insight into how staff specifically worked and wanted to work, he commented.

Moreover, as a consequence of not having been involved during the competition phase, building on the design concept without having access to the thoughts of the previous architect (who left the firm) was not straightforward, Nick explained in the interview. An abstract concept such as "openness", which had been requested by the client and central to the competition entry, proved difficult to elaborate. Attempts to translate this into more concrete concepts such as transparency and landscape offices did not match the way the staff wanted to work.

\subsection{Collecting first-hand information}

Nick had therefore organised a small-scale field study to obtain a better understanding of the project requirements, he told in the interview. He had visited the existing town hall and spent one day observing and questioning the people working there. According to Nick, conducting fieldwork is rather unusual for architects to do. ${ }^{2}$ Although minimising the validity of his study, because of his unfamiliarity with the "rules" concerning user studies, he highly valued the insights gained:

\footnotetext{
${ }^{2}$ Nick explained that the architecture firm in which he used to work conducted surveys amongst teachers for the design of a school, yet that this is not common practice amongst architects. He conducted the fieldwork on his own initiative and before the researcher joined the architecture firm.
} 
"Well, it's of course, when you go around to people to ask [some questions], some start telling their life story ... so then you're thinking oops (laughs). Well, no, I don't mind, but you don't get directly the input you were looking for. But on the other hand it gives you more insight into how people work. And apart from the fact [that they tell their life story], you actually also see the environment in which they work. So even if they tell you their life story, which doesn't relate directly to architecture, you do see how they work. I think it's enriching to see that. Because otherwise, I think the most dangerous thing as an architect, what many architects do and what is inevitable I think, is that you start from assumptions. You assume a lot. You think "that's a good idea", but sometimes in reality it doesn't work. Therefore it's good to have some kind of information from the client themselves, [about] how they are organised and work right now. ... There should be a certain openness to look at things and to have a bit of a sense of reality actually. Because otherwise, you can come up with the most fantastic concepts or ideas, but if it doesn't work out for that specific client or target audience, then it's not really okay." (Nick)

This testimony illustrates Nick's genuine interest in, and respect for, users. Apart from gaining insight into the staff's everyday activities, the interaction also allowed him to add some hierarchy to the requirements, and even verify reactions to potential design solutions.

Yet at the same time, the full potential of his user study was not exploited. Although Nick indicated that he was interested in spatial information, the study was reported in a table that lists the requirements for every department (Figure 1). Observations and document analysis suggest that the medium of a table was chosen because it fit in with the textual type of reports that were used in official communication between architects and clients. It did not seem to fit architects' designerly ways of working. Nick admitted that it was even not communicated within the design team.

\begin{tabular}{|c|c|c|c|c|}
\hline $2^{\text {nd }}$ floor & Occupation & Office material & Way of working & Remarks \\
\hline $\begin{array}{l}\text { Environment } \\
\text { Department }\end{array}$ & 2 Full-timers & $\begin{array}{l}1 \text { big desk } \\
1 \text { wall with medium- } \\
\text { high cabinets } \\
1 \text { wall with high } \\
\text { cabinets } \\
\text { Enough cabinets } \\
\text { Chilly space during } \\
\text { winter, also little } \\
\text { daylight }\end{array}$ & $\begin{array}{l}\text { Receive less citizens, } \\
\text { received at the desks } \\
\text { No need for a reception } \\
\text { In the future maybe an } \\
\text { increase in citizen } \\
\text { contacts when the DifTar } \\
\text { system will be established } \\
\text { in the recycling park } \\
\text { (SME's will need to pick } \\
\text { up a badge) }\end{array}$ & $\begin{array}{l}\text { Staff will be } \\
\text { integrated in } \\
\text { the Town } \\
\text { and Country } \\
\text { Planning } \\
\text { Department }\end{array}$ \\
\hline
\end{tabular}

Figure 1 This table extract (concerning the municipality's Environment Department) illustrates how Nick reported on his field study in the current town hall (translated by the authors).

\subsection{Fixating requirements}

The form of the table might be partly accountable for the reduction of the rich information from Nick's field study into a fixation on measures in his following design process. For example, in his aim to live up to what he understood to be the client's wishes, Nick tried to 
fixate the number of linear meters of cabinets required for each department, and provide this in his design. What followed was a meticulous process of puzzling the specific requirements into a design proposal. During the days before an important meeting with the client, the researcher observed how Nick made several phone calls to client representatives to check how he could adjust other requirements as to fit in all the cabinets asked for. In the car to the meeting with the client representatives, the partner involved in the design project asked Nick to quickly calculate the number of cabinets in their design proposal one last time. Nick was messing about with the documents in the passenger seat for a while, until fortunately the calculator indicated that the requirements were met.

In the meeting, which the researcher also attended, however, the client representatives commented that certain departments had too many cabinets. The architects were disappointed that the requirements they had held on to turned out to be not that important. They seemed unamused with yet another change of requirements. The importance attached to fixed requirements relates to architects' ways of working. As designing is such a complex activity, architects first need to set the boundaries of the space in and in relation to which they can develop solutions. As Nick explained:

"it's a support that is practical because you have a kind of starting point. ... So, that part of organisation and square meters, that's something that has to be done, I think. And after that ... you start with the atmosphere or architecture. But first the preconditions should be right." (Nick)

\subsection{Puzzling (together) with users}

An alternative way of representing user requirements that is more in line with architects' skills was observed in Nick's design materials. In an early design stage, Nick was drawing schematic floor plans (Figure 2), with abstract building blocks that represented programme units and that could be configured into the building's layout like a puzzle. This translation is visual and dynamic, which made it suitable in the reflective practice of designing. As Nick explained, "you can say 'we remove one office' and then you strike it out with a marker, so to speak".

The schematic floor plans also proved a useful tool in meetings with the client representatives. In the interview, Nick stressed the importance of having concrete material to talk about. The (schematic) floor plans, but also physical or virtual models and renderings become the objects of discussion. As those objects display potential design solutions, they provoke immediate and concrete feedback. Moreover, when they can be manipulated, clients are drawn into the reflective design process, proposing, discussing and evaluating different alternatives together with the architects. In the meeting with the client representatives, it was observed, e.g., how the schematic floor plans were used to renegotiate the capacity (e.g., the number of meeting rooms) and room typology (e.g., landscape office) in terms of spatial efficiency. 


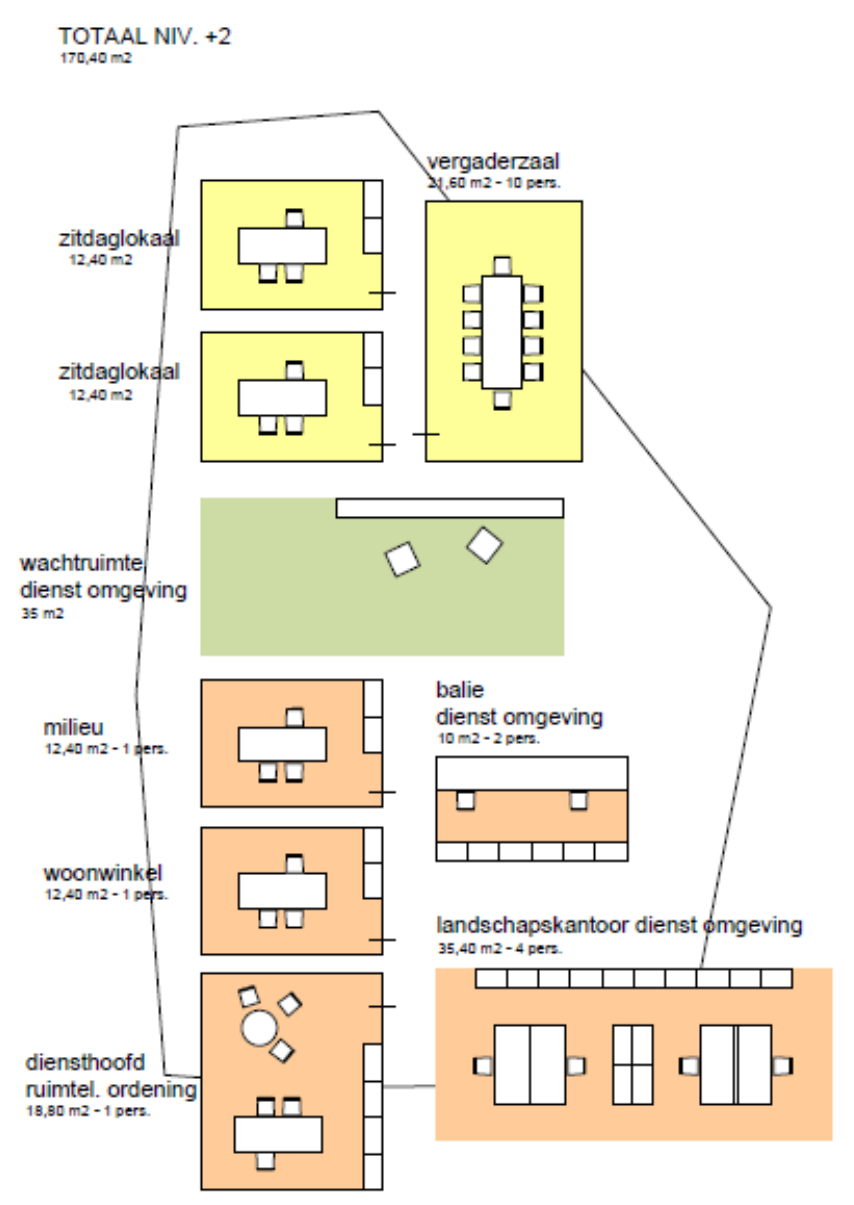

Figure 2 This schematic floor plan with programme units (representing the second floor of the town hall's new extension), which Nick made to develop the building's programme and design, proved a useful tool in meetings with the client representatives.

\section{Insight into designerly ways of knowing}

The fieldwork account of Nick's quest to understand users' needs in the design of a new town hall provides insight into the social and material aspects of architects' designerly ways of knowing about users.

We first observed how acquiring knowledge about users through a traditional design brief was ineffective, and how Nick alternatively collected first-hand information from users himself through a small-scale field study in the current town hall. His appreciation of the contextualised information about how people's jobs are organised in relation to their environment gives us insight into the information content that is relevant to architectural design practice. Yet, internal communication problems hampered the knowledge flow in the architecture firm. For instance, knowledge acquired during the competition stage stayed with the architect who left the firm and one of the partners, knowledge generated through the small-scale field study stayed with Nick. Our observations suggest that these problems result from a lack of organised knowledge sharing in the firm (a social aspect) combined with a lack of adequate ways to represent this knowledge (a material aspect). 
We also observed how the knowledge generated through Nick's small-scale field study was transformed into requirements that largely relate to spatial dimensions (e.g., linear and square meters of cabinets and office spaces) and relations (e.g., whether office spaces should be open to the public, or shared with colleagues). Nick generated further knowledge about the implications of design decisions by iteratively testing different options in sketches and schemes. This understanding through design materials is an essential activity in architects' design process (cf. Schön 1983). It also has a social aspect, as we observed how the partner of the firm interacted with Nick through these design materials as well, the building design was collaboratively negotiated.

Yet, we finally observed how requirements had to be re-negotiated in a meeting with the client, as architects' transformation of what they understood to be users' needs into concrete design features did not correspond to the wishes of the client representatives. Here again, the material representation of users' needs into easy-to-manipulate schematic floor plans played an important role. As non-designers, client often have difficulties with reading floor plans. The recognisable and unfixed programme units allowed them to collaboratively explore spatial relationships between the programme units and further develop the building's programme. This "client learning" (Siva and London 2011) might account for their disagreement with architects' proposal and seemingly change of early requirements.

Our findings indicate that informing architects includes more than just providing static information through reports. It is also a dynamic process that involves design materials and interactive relationships with stakeholders. We refer once again to the schematic floor plans to illustrate materials' ability to mediate attention for users in a designerly and even collaborative way (cf. Ewenstein and Whyte 2009; Luck 2007).

Judging from this fieldwork account, information formats based on architects' own design skills and materials may hold the potential to communicate and further investigate specific user needs in an interactive and design-oriented way. This is difficult with the reports or lists of requirements that are typically used in architectural practice, as observed in the fieldwork. We identified potential, however, in architects' creative skills to imagine and represent spatial experience. Making users' experiences explicit in design materials enables negotiation (e.g., with clients), which can enhance attention to user needs.

Our call to mobilise architects' design expertise (e.g., their representational skills, cf. Kasalı and Nersessian 2015) challenges architects' as well as researchers' role in knowledge transfer. The advantage of an ethnographic research approach is that it provides a way to map the socio-material mediators of knowledge about users. These are the preconditions of architectural design practice with which novel information formats should tie in. 


\section{Reflection on the research approach}

\subsection{Possibilities}

In ethnographic fieldwork, the researcher's identity plays an important role. The first author's profile turned out to be appropriate. Whereas her studies in architectural engineering provided a shared background, enabling her to understand the language of this culture of practice, her lack of professional experience seemed to invite participants to explain the particularities of architectural practice, as if she were an intern that had to be instructed. Also non-professional aspects (e.g., a shared music taste) allowed her to develop a relationship. Particularly the joined lunches provided access into the community. Overall, the researcher was able to build up rapport.

The pilot study also provided an opportunity to develop observational techniques. During discussions amongst participants, the researcher paid attention not to be intrusive. Plunging into design documentation proved useful at these moments. Only during in-depth interviews, she played out her role as a researcher, including visible note-taking and audio recording. The personal focus on interviewees made them feel that their opinions were valued. Moreover, because the interviews took place behind closed doors, they had an air of mystery, making some participants curious and willing to participate. The interviews provided the researcher a moment to step back and take some distance from the field. Also participants appreciated the opportunity to reflect upon their way of working. As one of them remarked, "(astonished) It's actually the first time I think about this. I think it's interesting, yes, I do". In her ethnography of the Office for Metropolitan Architecture (OMA), Yaneva (2009, pp.30-35) similarly describes the benefits of observing "at two different distances".

The ethnographic fieldwork techniques proved valuable to study how knowledge about users is generated, shared, transformed and represented in the design process. Only by assembling the data from different techniques, the meaning of the situation could be more fully grasped. For example:

- according to architects' statements in the interviews, not all documentation provided proved useful in the design process (e.g., the 40-page concept note), which could not be concluded from analysing the design materials alone;

- on the other hand, architects themselves seemed not to be fully aware of the potential of their designerly ways of representing and working with user needs, as observed by the researcher (e.g., the easy-to-manipulate schematic floor plans).

This interpretation based on assembling data from different sources is key to ethnographic research. The role of (design) materials was certainly more than being the tangible evidence of architects' design process. Materials also served as probes to elicit more explanations or narratives by participants, making them crucial to the research methodology. 


\subsection{Limitations}

Although the researcher's background made it easier for her to understand architects' language, we should remark that it was not always easy to grasp the meaning of design materials without explanation. This was also mentioned by a participant in the fieldwork account above. The difficulty does not relate to understanding conventions, but to certain materials' role of design medium rather than communication means. However, the aim was not to conduct an isolated document analysis, but to assemble different sources. In this respect, the design materials also served as occasion to ask participants for explanation, as mentioned.

The main limitations of the fieldwork relate to timing. The researcher had planned a parttime presence in the architecture firm, to allow simultaneous data collection and processing and adjusting both. However, being present at a particular meeting proved challenging, as architects' planning tended to change constantly. Moreover, a part-time presence made it difficult to participate in design activities. The researcher could only perform ad-hoc tasks (e.g., assisting in making a scale model) not requiring a full-time presence. Her timing was never synchronised to that of the firm - an issue also Yaneva $(2009$, p.35) experienced.

Timing is a challenge that deserves further attention in future studies. When the researcher finally managed to attend an external meeting with client representatives, this meeting provided extremely interesting data. Indeed, the starting points of the approach signal the importance of architects' social environment. Therefore, in future studies, more attention will be paid to expanding the research field beyond the architecture firm, as to include clients' and other stakeholders' perspectives.

\section{Conclusion}

This paper confirms design researchers' assertion that an ethnographic research approach allows for an in-depth understanding of architectural design practice. The fieldwork account gives outsiders a feel of the kind of issues architects need to handle in daily practice. Moreover, it shows the added value of a research approach that takes into account the socio-material environment (which is reflected in the findings), instead of just focusing on information characteristics isolated from the practice in which it is used.

Findings indicate that informing architects about users' experiences includes more than just providing static information (e.g., through reports). It is also a dynamic process that involves design materials and interactive relationship (e.g., in a design team, between architects and clients). An ethnographic research approach provides a way to map the socio-material mediators of knowledge about users. These mediating aspects that characterise architects' design practice are key in addressing the challenge of transferring knowledge about users' experiences into architectural design practice.

Insight into how knowledge about users is embedded in architects' ways of working is expected to inform the development of new, tailored formats for informing architects about 
users' experiences. Mobilising architects' creative skills is identified an opportunity for more effective knowledge transfer. This challenges architects' as well as researchers' role in transferring knowledge about users' experiences from research into practice.

In our future research we will conduct more studies, in a variety of architecture firms (working on diverse projects), in order to acquire a better understanding of their (different) designerly ways of knowing about users. Combining this with an analysis of the potential of information formats from other design disciplines, is expected to inform the development of design-oriented formats to foster insight, empathy and innovation in architectural design.

Acknowledgements: The authors would like to thank the architecture firm for their participation in the study. This research received support from the Research Fund KU Leuven (OT/12/051) and the Research Foundation - Flanders (FWO).

\section{References}

Annemans, M., Van Audenhove, C., Vermolen, H., and Heylighen, A. (2014) How to introduce experiential user data: The use of information in architects' design process, in Lim, Y.-K., Niedderer, K., Redström, J., Stolterman, E. and Valtonen, A. (eds.), Proceedings of DRS 2014: Design's Big Debates, Umeå, Sweden, Design Research Society, pp. 1626-1637.

Ball, L. J., and Ormerod, T. C. (2000) Applying ethnography in the analysis and support of expertise in engineering design, Design Studies, 21, pp. 403-421.

Boas, F. (1920) The methods of ethnology, American Anthropologist, 22(4), pp. 311-321.

Bogers, T., van Meel, J., and van der Voordt, T. (2008) Architects about briefing:

Recommendations to improve communication between clients and architects, Facilities, 26, pp. 109-116.

Bucciarelli, L. L. (1988) An ethnographic perspective on engineering design, Design Studies, 9, pp. 159-168.

Christensen, L. R. (2013) Apprenticeship and visual skills, in Coordinative Practices in the Building Process: An ethnographic perspective, Springer, pp. 65-78.

Crilly, N., Maier, A., and Clarkson, P. J. (2008) Representing artefacts as media: Modelling the relationship between designer intent and consumer experience, International Journal of Design, 2(3), pp. 15-27.

Cross, N. (2006) Designerly Ways of Knowing, Springer.

Cuff, D. (1992) Architecture: The story of practice, MIT Press.

Diaz Moore, K., and Geboy, L. (2010) The question of evidence: Current worldviews in environmental design research and practice, Architectural Research Quarterly, 14, pp. 105-114.

Dong, H., McGinley, C., Nickpour, F., and Cifter, A. S. (2015) Designing for designers: Insights into the knowledge users of inclusive design, Applied Ergonomics, 46, pp. 284-291.

Dorst, K. (2006) Understanding Design: 150 reflections on being a designer (2nd edition), BIS Publishers.

Ewenstein, B., and Whyte, J. (2009) Knowledge practices in design: The role of visual representations as 'epistemic objects', Organization Studies, 30, pp. 7-30. 
Formosa, D. (2009) Six real people, in Lee, K., Kim, J. and Chen, L.-L. (eds.), IASDR 2009: Design / Rigor and Relevance, Seoul, South Korea, Korean Society of Design Science, pp. 4381-4386.

Goodman, J., Langdon, P., and Clarkson, P. J. (2006) Providing strategic user information for designers: Methods and initial findings, in Clarkson, P. J., Langdon, P. and Robinson, P. (eds.), Designing Accessible Technology, Springer, pp. 41-51.

Gray, D. B., Gould, M., and Bickenbach, J. E. (2003) Environmental barriers and disability, Journal of Architectural and Planning Research, 20, pp. 29-37.

Heylighen, A., and Nijs, G. (2014) Designing in the absence of sight: Design cognition rearticulated, Design Studies, 35, pp. 113-132.

Imrie, R. (2003) Architects' conceptions of the human body, Environment and Planning D: Society and Space, 21, pp. 47-65.

Kasalı, A., and Nersessian, N. J. (2015) Architects in interdisciplinary contexts: Representational practices in healthcare design, Design Studies, 41, pp. 205-223.

Kirkeby, I. M. (2009) Knowledge in the making, Architectural Research Quarterly, 13, pp. 307-313.

Kirkeby, I. M. (2015) Accessible knowledge - Knowledge on accessibility, Journal of Civil Engineering and Architecture, 9, pp. 534-546.

Kornberger, M., Kreiner, K., and Clegg, S. (2011) The value of style in architectural practice, Culture and Organization, 17, pp. 139-153.

Latour, B., and Woolgar, S. (1986) Laboratory Life: The construction of scientific facts (2nd edition), Princeton University Press.

Lawson, B. (1994) Design in Mind, Butterworth-Heinemann.

Lera, S., Cooper, I., and Powell, J. A. (1984) Information and designers, Design Studies, 5, pp. 113-120.

Lloyd, P. (2000) Storytelling and the development of discourse in the engineering design process, Design Studies, 21, pp. 357-373.

Luck, R. (2007) Using artefacts to mediate understanding in design conversations, Building Research \& Information, 35, pp. 28-41.

Malinowski, B. (1984) Subject, method and scope, in Argonauts of the Western Pacific: An account of western enterprise and adventure in the archipelagoes of Melanesian New Guinea, Waveland Press, pp. 4-25. (Original work published 1922)

Newland, P., Powell, J. A., and Creed, C. (1987) Understanding architectural designers' selective information handling, Design Studies, 8, pp. 2-16.

Nickpour, F., and Dong, H. (2011) Designing anthropometrics! Requirements capture for physical ergonomic data for designers, The Design Journal, 14, pp. 92-111.

Rashid, M. (2013) The question of knowledge in evidence-based design for healthcare facilities: Limitations and suggestions, HERD: Health Environments Research \& Design Journal, 6(4), pp. 101-126.

Redström, J. (2012) Introduction: Defining moments, in Gunn, W. and Donovan, J. (eds.), Design and Anthropology, Ashgate, pp. 83-99. 
Rittel, H., and Webber, M. (1973) Dilemmas in a general theory of planning, Policy Sciences, 4, pp. 158-167.

Schön, D. A. (1983) The Reflective Practitioner: How professionals think in action, Basic Books.

Siva, J., and London, K. (2011) Investigating the role of client learning for successful architect-client relationships on private single dwelling projects, Architectural Engineering and Design Management, 7, pp. 177-189.

Tétreault, M.-H., and Passini, R. (2003) Architects' use of information in designing therapeutic environments, Journal of Architectural and Planning Research, 20, pp. 48-56.

Valkenburg, R., and Dorst, K. (1998) The reflective practice of design teams, Design Studies, 19, pp. 249-271.

Van der Linden, V., Annemans, M., and Heylighen, A. (2016) Architects' approaches to healing environment in designing a Maggie's Cancer Caring Centre, The Design Journal, 19, in press.

Vinck, D. (ed.) (2009) Everyday Engineering: An ethnography of design and innovation, MIT Press.

Watson, T. J. (2011) Ethnography, reality, and truth: The vital need for studies of 'how things work' in organizations and management, Journal of Management Studies, 48, pp. 202217.

Weytjens, L., Verdonck, E., and Verbeeck, G. (2009) Classification and use of design tools: The roles of tools in the architectural design process, Design Principles and Practices: An International Journal, 3, pp. 289-302.

Yaneva, A. (2009) The Making of a Building: A pragmatist approach to architecture, Peter Lang.

\section{About the Authors:}

Valerie Van der Linden, $\mathrm{PhD}$ candidate at the Research[x]Design group at KU Leuven, aims to develop design-oriented formats to inform architects about diverse people's spatial experiences. Her research is funded by a PhD fellowship of the Research Foundation - Flanders (FWO).

Hua Dong is professor in Design and Innovation at Tongji University and founder of the Inclusive Design Research Group. She obtained a PhD from the University of Cambridge and lectured at Brunel University. She coordinates the Design Research Society InclusiveSIG.

Ann Heylighen is a research professor and co-chair of the Research[x]Design group at KU Leuven. She obtained a PhD in Leuven and conducted research at Harvard University and UC Berkeley. Currently, her research focuses on spatial experience as source of design knowledge. 